\title{
A Integração dos Estudantes de Periferia no Curso de Física: razões institucionais da evasão segundo a origem social
}

\section{The Integration of Students from the Outskirts into the Physics Program: institutional reasons for dropout according to social background}

\author{
Paulo Lima Junior ${ }^{1}$ \\ Jailton Correia Fraga Junior ${ }^{1}$ \\ Vanessa Carvalho de Andrade ${ }^{1}$ \\ Pedro Rogério Pinheiro Bernardino' \\ 'Universidade de Brasília (UnB), Instituto de Física, Brasília, DF, Brasil. \\ Autor correspondente: paulolimajr@unb.br
}

Resumo: A falta de integração acadêmica e social tem sido considerada importante para explicar as razões institucionais que produzem evasão. Neste artigo, investigamos as relações entre a integração dos estudantes do Instituto de Física da Universidade de Brasília e sua origem social. Um instrumento baseado no modelo de Tinto foi elaborado e aplicado a uma amostra representativa do corpo discente $(n=160)$. A evidência indica que: (1) entre os ingressantes, a ocorrência de motivação para a docência é independente da motivação para pesquisa; (2) os estudantes intelectualmente mais confiantes são os mesmos que reportam um convívio mais regular e agradável com os colegas; (3) os estudantes de periferia tendem a ser menos integrados social e academicamente, ainda que não existam diferenças motivacionais significativas entre eles e os estudantes mais privilegiados ao ingressar no curso. Em conjunto, os resultados recomendam um olhar mais sensível aos desdobramentos das diferenças sociais sobre as relações humanas nos Institutos de Física.

Palavras-chave: Evasão escolar; Ensino superior; Classe social; Problemas socioeducacionais.

Abstract: The lack of academic and social integration has been considered important to explain the institutional reasons for student dropout. In this paper, we investigate the relationship between the integration of students of the Institute of Physics of UnB and their social background. An instrument based on the Tinto model was elaborated and applied to a representative sample of the student body $(n=160)$. Evidence indicates that: $(1)$ among the freshmen, the occurrence of motivation for teaching is independent of the motivation for research; (2) we should suspect the belief that enjoying social life competes with academic success, since intellectually confident students are also those who report more regular and enjoyable social life with peers; (3) outskirt students tend to be less socially and academically integrated. Taken together, the results recommend a sensitive look at the unfolding of social differences on human relations in the Physics Institutes. problems.

Keywords: Dropout; Social background; Higher education; Socio-educational 


\section{Introdução}

Ao longo dos últimos anos, as universidades federais passaram por um processo de transformação que coloca novos desafios à educação científica. A expansão do acesso às Instituições Federais de Educação Superior (IFES), seja por meio do aumento do número de vagas oferecidas, seja pela lei de cotas, tem contribuído para uma presença mais expressiva de estudantes de periferia ${ }^{1}$ nas universidades públicas (RISTOFF, 2013). Para além do resultado bastante conhecido de que estudantes de classe popular tendem a apresentar desempenho inferior nas avaliações de conhecimento em todo o mundo (OECD, 2016), análises das pontuações obtidas pelos estudantes brasileiros no Exame Nacional do Ensino Médio indicam que os itens de Física são particularmente capazes de discriminações sociais (KLEINKE, 2017; LIMA JUNIOR, 2015). Esse resultado é consistente com a perspectiva de que o sistema escolar contribui para a consagração cultural dos jovens mais privilegiados em cada formação social (BOURDIEU, 2007) e, ao mesmo tempo, reforça a intuição de que as disciplinas popularmente reconhecidas como mais difíceis ou "duras" são as mais efetivas em discriminar os estudantes segundo sua origem.

Em vista da relação típica entre desempenho escolar e origem social (relação essa que jamais poderia ser explicada sem levarmos em consideração a organização do sistema de ensino e as especificidades de cada área de conhecimento), as expectativas razoáveis para as políticas de cotas raciais nas universidades poderiam não ser as mais otimistas. No entanto, temos observado que as universidades públicas responderam relativamente bem à política de cotas raciais. Ainda que os estudantes negros e pardos enfrentem experiências de discriminação (LEMOS, 2017), cotistas têm atingido o mesmo desempenho dos não-cotistas nas avaliações do Exame Nacional de Desempenho de Estudantes (ENADE) ao concluir o curso (WEINER; MELGUIZO, 2018). Diferenças de desempenho entre cotistas e não-cotistas podem ser observadas inicialmente (PEIXOTO, 2016), mas vão se reduzindo ao longo do tempo. Esse resultado indica alguma contribuição das universidades federais na redução da distância escolar entre jovens brancos e negros.

Por outro lado, é verdade que, para uma análise crítica da efetiva inclusão social promovida pelas políticas de acesso às universidades federais, o desempenho escolar dos estudantes graduados não pode ser analisado separadamente das taxas de evasão. Afinal, se os cursos de graduação eliminarem mais os estudantes da periferia que os privilegiados, não surpreenderá se, após a superseleção dos mais vulneráveis (BOURDIEU; PASSERON, 1992)² , todos os sobreviventes apresentarem o mesmo desempenho escolar.

Análises têm apontado que as taxas de evasão da educação superior de cotistas são iguais ou superiores à taxa dos não-cotistas (MENDES JUNIOR, 2014). Ao mesmo tempo, no curso de Física da Universidade Federal do Rio Grande do Sul (UFRGS), não foi encontrada relação estatisticamente significativa entre origem social e as taxas de evasão (LIMA JUNIOR; OSTERMANN; REZENDE, 2018). Está claro que este resultado não foi (nem poderia ter sido)

\footnotetext{
${ }^{1}$ Neste texto, a palavra periferia não designa imediatamente o conjunto das localidades mais afastadas do centro da cidade, mas o 'lugar' social dos grupos que, marginalizados pelas relações de classe e cor, são compostos predominantemente por famílias pobres, negras e pouco escolarizadas. Em algumas formações urbanas essa periferia social reside também no centro da cidade.

${ }^{2}$ Chama-se superseleção a eliminação proporcionalmente mais intensa das populações menos privilegiadas ao longo das etapas seletivas do sistema educacional. Ela contribuiria, portanto, para uma aparente redução da desigualdade social no universo daqueles que lograram ingressar e permanecer no ensino superior.
} 
suficiente para eliminar a suspeita de que a integração dos estudantes no curso de Física dáse de forma diferente para os jovens menos privilegiados. Um olhar atento à vulnerabilidade social nos cursos de graduação geralmente mostra (a despeito do que possam dizer quaisquer estatísticas) que as experiências dos estudantes na instituição dependem das vantagens culturais que sua história de vida (não) Ihes permitiu acumular (CEREZO, 2018).

Ao contrário do que ocorre na educação básica, as taxas de evasão das universidades federais não costumam ser indicadores muito sensíveis às diferenças de classe dos estudantes, visto queas razões quelevam osestudantes a abandonaro curso nem sempre estão relacionadas à vulnerabilidade social (RISTOFF, 1995). Há muitos estudantes que abandonam seus cursos por encontrarem oportunidades mais atraentes fora dele. Devido à complexidade própria da educação superior, as taxas de evasão reúnem estudantes vulneráveis e privilegiados; pessoas que abandonam seu curso por fracasso e por ambição. Temos visto que os cursos de graduação nas áreas de ciência básica (com destaque para o curso de Física) apresentam historicamente os índices de evasão mais elevados de sua instituição (SILVA FILHO, 2007). Não é difícil argumentar que tais cursos satisfazem simultaneamente duas condições: (1) não admitem a permanência de estudantes de baixo desempenho escolar; (2) falham em reter grande parte dos estudantes mais distintos e ambiciosos, que preferem migrar para carreiras mais promissoras que a científica.

Mesmo sendo muito diferentes as razões que levam ao abandono da graduação, a integração acadêmica e social dos estudantes tem sido abordada como um elemento-chave da vida institucional capaz de contribuir para a permanência do estudante no curso. Afinal, quanto mais integrados aos sistemas acadêmico e social da instituição de ensino, menor será a probabilidade de que um estudante abandone seu curso de graduação por causa de experiências imputáveis à sua relação com a instituição (TINTO, 1994). De fato, os casos de evasão que resultam de escolhas profissionais mais ambiciosas não deveriam ser tratados junto com aqueles que resultam da fragilidade dos estudantes diante da austeridade institucional, de dificuldades no convívio com os colegas e fracasso nas avaliações. Por todas essas razões, a análise exclusiva das taxas de evasão não é o meio mais efetivo de captar o que ocorre no dia-a-dia da instituição de ensino.

Neste artigo, buscando superar as limitações de algumas pesquisas sobre evasão da educação superior, sobretudo aquelas baseadas exclusivamente em análises de taxas de evasão (SILVA FILHO, 2007), reportamos os resultados da construção de um questionário de integração social e acadêmica, que, aplicado aos alunos do curso de Física da Universidade de Brasília (UnB), permitiu, além de testar o modelo segundo o qual a integração acadêmica e social é o preditor mais importante das razões institucionais da evasão discente (TINTO, 1994), avaliar em que medida o curso de Física é bem sucedido na integração social e acadêmica dos estudantes de periferia. Portanto, nossa questão de pesquisa pode ser formulada nos seguintes termos: em que medida a integração acadêmica e social dos estudantes do Instituto de Física da UnB varia segundo a origem social desses estudantes?

Resultados obtidos devem nos ajudar a compreender melhor os efeitos da origem social sobre a evasão dos cursos de graduação. A tomada de consciência de como essas diferenças sociais se enraízam no espaço da instituição de ensino pode ser decisiva para que os atores responsáveis tomem decisões socialmente sensíveis e capazes de reduzir ao mínimo os efeitos reprodutores que se observam sistemicamente na educação superior. 


\section{Referencial Teórico}

Na década de 1970, Tinto (1994) propôs um modelo para a análise da evasão na educação superior que se tornou paradigmático nas décadas seguintes (BRAXTON; HIRSCHY; MCCLENDON, 2004; PASCARELLA; TERENZINI, 1991). Recentemente, esse modelo tem sido empregado, no Brasil, pela pesquisa em educação científica para compreender, principalmente, a evasão dos cursos de Física e Química (KUSSUDA, 2017; LIMA JUNIOR; OSTERMANN; REZENDE, 2018; MASSI; VILLANI, 2015; RIBEIRO, 2015). Além de ser academicamente produtivo, o modelo de Tinto permite orientar a ação da instituição no que diz respeito à manutenção dos estudantes no curso. Podemos dizer que se trata de um modelo interacionista no sentido em que não imputa a evasão exclusivamente à vontade do estudante, tampouco à configuração da instituição de ensino. Afinal, é principalmente na relação estabelecida entre estudante e instituição que se encontram as razões propriamente institucionais para a escolha de abandonar o curso ou permanecer nele.

Com respeito à instituição de ensino, Tinto (1994) identifica dois sistemas: (1) o acadêmico e (2) o social. O sistema acadêmico diz respeito ao conjunto de todas as atividades (formais ou informais) orientadas à formação dos estudantes. Fazem parte desse sistema: as atividades em disciplinas teóricas e experimentais, projetos de iniciação científica, tarefas de casa e estudo com os colegas, participação nas provas e avaliações de desempenho. 0 sistema social, por outro lado, consiste de todas as atividades que integram a vida comum dos estudantes. Geralmente são atividades de convivência, tais como: alimentação no restaurante universitário, prática esportiva, participação política e convívio nos diretórios estudantis, festas e vida cultural.

Os sistemas acadêmico e social podem ser bastante assimétricos, mas estão sempre interligados. Nas universidades americanas tradicionais, onde muitos estudantes moram em repúblicas organizadas pela própria instituição, o sistema social é bastante robusto e institucionalizado. Porém, em outras instituições de ensino superior, encontramos um sistema social mais informal e difuso. Em todos os casos, a evidência indica que o convívio com os colegas e professores fora das atividades de ensino é importante para que os alunos construam um senso de pertencimento à instituição eventualmente decidindo permanecer no curso mesmo quando há motivos para abandoná-lo.

O modelo de Tinto (1994) propõe que a integração do estudante à instituição de ensino seja fundamental para evitar a evasão. Estudantes mais integrados tenderiam a permanecer no curso. Há, portanto, dois tipos de integração. A integração acadêmica estaria relacionada à participação nas atividades formativas do curso. É esperado que os estudantes integrados academicamente identifiquem-se com as disciplinas do curso, sentindo-se participantes legítimos e competentes. É também esperado que se sintam reconhecidos pelos professores e colegas como sujeitos capazes, estando particularmente comprometidos e vinculados ao curso no qual estão matriculados. A integração social, por outro lado, diz respeito à boa relação com os demais. Estudantes integrados socialmente devem reportar um convívio saudável e agradável com professores e colegas de curso. Devem sentir que fazem parte do grupo de pessoas que ali aprendem e ensinam mesmo quando não estão envolvidos em atividades estritamente acadêmicas. É esperado que eles participem dos encontros festivos e descontraídos que também fazem parte da vida numa universidade. 
Finalmente, Tinto (1994) afirma que o estudante ingressa no curso de graduação com alguns interesses e com uma disponibilidade, maior ou menor, a se comprometer com as atividades do curso. De forma genérica, designamos esse conjunto de elementos de entrada como "motivações". A motivação para o curso em cada indivíduo seria atualizada e transformada por meio das suas experiências de integração social e acadêmica. As experiências de integração seriam responsáveis por transformar as motivações de ingresso numa decisão mais madura e informada, orientando os estudantes a permanecer no curso ou abandoná-lo. Portanto, de forma muito sintética, o modelo de Tinto poderia ser simplificado conforme mostra a Figura 1.

Figura 1 - Relações mínimas esperadas segundo o modelo de Tinto (1994)

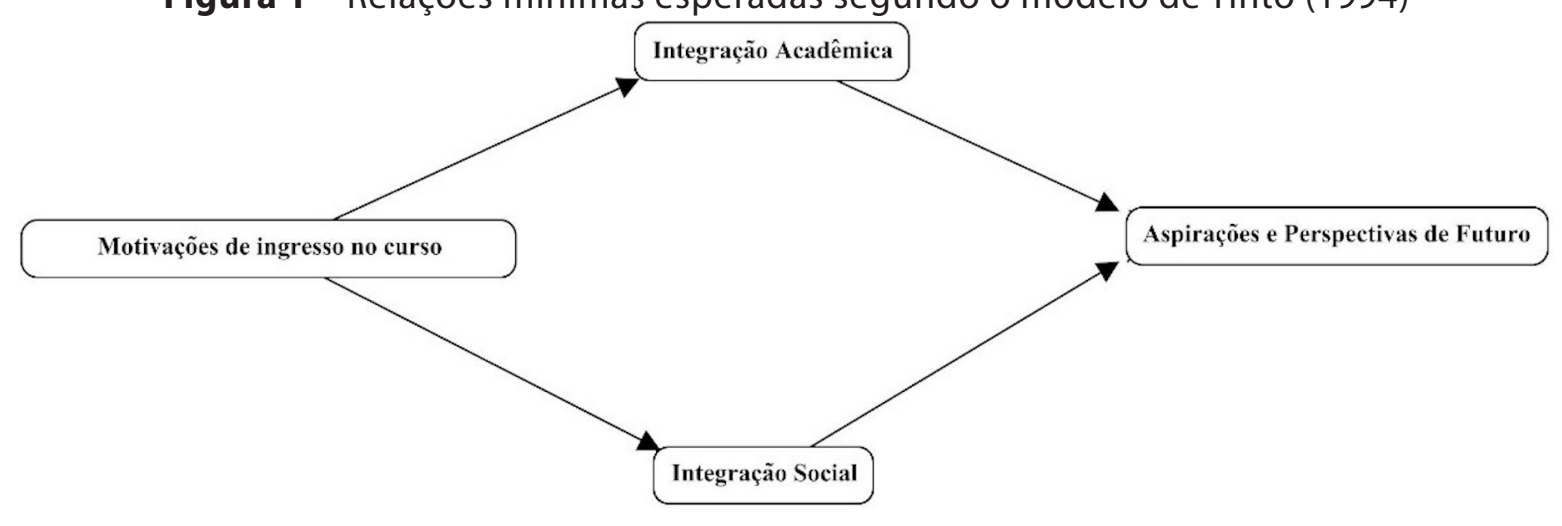

Fonte: elaborado pelos autores.

Integração acadêmica e social estão necessariamente associadas (TINTO, 1994), mas de que forma? Não é familiar a figura do estudante bon vivant que, justamente pelas relações agradáveis que mantém com seus colegas, tende a abandonar as atividades acadêmicas em favor das festas e da diversão? De fato, é usual que alguns atores da universidade considerem que a integração social pode funcionar como um obstáculo para o desempenho acadêmico do estudante. Faz parte do imaginário comum que o estudante mais bem sucedido no curso de Física seja justamente aquele que se integra menos às situações de convivência e diversão com os colegas, dedicando-se exclusiva e diligentemente às atividades formativas. Portanto, ainda que as duas formas de integração favoreçam a permanência, a relação entre integração social e acadêmica precisa ser resolvida empiricamente.

Não é incorreto afirmar que, além de outras limitações (BRAXTON; HIRSCHY; McCLENDON, 2004), o modelo de Tinto (1994), pelo seu próprio olhar institucional, não dá toda a atenção necessária às questões de classe que envolvem as trajetórias de jovens e adultos na educação superior. Afinal, em que medida a instituição de ensino - e os Institutos de Física, em particular - integram de forma diferenciada seus estudantes em função da sua origem social?

Essa questão foi, de alguma maneira, colocada já por Lima Junior, Ostermann e Rezende (2018) ao conjecturarem que, embora a probabilidade de evasão seja a mesma em todos os estratos sociais do Instituto de Física da UFRGS, as razões que levariam os estudantes a abandonar o curso seriam diferentes: a evasão estaria mais relacionada ao fracasso escolar para estudantes de classe popular, mas mais relacionada à ascensão social entre os filhos da classe média e dominante. No entanto, o referido estudo não faz mais que conjecturar algo que precisa ser investigado detalhadamente: em que medida os estudantes são mesmo integrados ao curso de graduação em Física segundo sua origem social? 
É um argumento comum à sociologia da educação que a associação observada nos sistemas educacionais de todo o mundo entre origem social e trajetória escolar (MONT'ALVÃO, 2011) não se explica somente pelas relações de classe nem pelas relações escolares, mas pelas relações entre esses dois sistemas de relação (BOURDIEU, 2007). De fato, uma análise mais ampliada não se depara somente com uma configuração especificamente excludente nos sistemas educacionais, mas com estratégias típicas de investimento escolar que, em cada família, contribuem para reproduzir, nos filhos, uma posição social relativamente próxima à dos pais.

Segundo Bourdieu (2007), as estratégias mais agressivas de investimento escolar encontram-se nas frações da classe média que, tendo ascendido da classe popular por meio da escola, vivem entre o medo da desclassificação e a esperança de dar continuidade ao seu projeto de ascensão. São essas as famílias mais propensas a ter menos filhos (o que veio a ser chamado de malthusianismo) como estratégia de investir seus recursos em uma prole menos numerosa. Também são essas famílias mais propensas ao rigorismo e à boa-vontade cultural necessários ao investimento educacional de longo prazo.

Está claro que essas estratégias, ainda que bem ajustadas à origem social das famílias, não resultam sempre de um cálculo racional, mas da incorporação de um sistema de disposições (ou um princípio gerador de práticas) chamado habitus (BOURDIEU, 2007). É o habitus que, de forma sempre flexível, contribui para que as ações das famílias (ou, mais especificamente, suas estratégias de investimento escolar) sejam relativamente bem ajustadas à consecução do seu destino sociologicamente provável. Assim, os estudantes de origem popular não entrariam na universidade com diferenças exclusivamente financeiras ou escolares (tendo estudado em escolas precarizadas). Suas ações individuais estariam orientadas por estratégias diferentes (mais ou menos ambiciosas e rigoristas) de maneira que mesmo suas escolhas pessoais (por exemplo, conseguir um emprego que lhes permita sair logo da casa dos pais) podem reduzir suas chances de sucesso no curso. É verdade que a história escolar dos nossos estudantes deixa suas marcas e que muito do fracasso escolar na universidade se explica pela precariedade da educação básica à qual a maioria da população pobre tem acesso. Contudo, os estudantes de periferia não entram no curso de mãos vazias. Eles trariam, incorporadas a si, estratégias específicas de investimento. Se o argumento estiver correto, na medida em que a instituição de ensino selecionar os estudantes mais rigoristas, ela contribuiria para consagrar os filhos da classe média.

\section{Metodologia}

Para dar conta da questão de pesquisa, um instrumento foi desenvolvido com o propósito de avaliar o risco de evasão dos alunos do Instituto de Física da Universidade de Brasília, levando em consideração a vulnerabilidade social desses estudantes. Sua aplicação teve como propósito atingir o maior número de alunos do curso. O instrumento foi desenvolvido integralmente em colaboração com um grupo de estudantes do curso. Foi enviado a especialistas da área e passou por uma aplicação preliminar, visando sua validação.

A versão final do instrumento está dividida em duas partes. A primeira é uma adaptação do questionário socioeconômico que tradicionalmente integra o Exame Nacional de Desempenho de Estudantes (ENADE). A saber, as questões socioeconômicas típicas são de múltipla-escolha e demandam técnicas de análise voltadas a variáveis 
nominais (tais como a análise de contingência e de correspondência). A segunda parte do instrumento teve por objetivo avaliar os construtos do modelo de Tinto (motivação, integração e aspirações) em cada estudante da forma mais fidedigna possível. Optamos por empregar escalas de concordância tipo-Likert. O tratamento dessa parte de questionário foi feito principalmente por meio da análise fatorial e de consistência interna. Como a primeira parte do questionário envolve informações socioeconômicas presentes em outros instrumentos, publicamos somente a segunda parte no Apêndice deste artigo.

A aplicação definitiva do instrumento ocorreu nos horários de aula das disciplinas obrigatórias do curso de Física com todas as perguntas impressas em papel. Foram obtidas 160 respostas anônimas (representando $40 \%$ de todos os estudantes matriculados). Após a aplicação, todas as respostas foram tabuladas manualmente e inseridas para tratamento no programa $\mathrm{R}$ por meio das bibliotecas psych, FactoMineR e missMDA. A análise foi realizada nas seguintes etapas:

(1) Avaliamos a consistência interna das escalas que constituem o Modelo de Tinto (segunda parte do questionário). Por meio da análise fatorial, construímos seis fatores que reduzem as respostas dos alunos às dimensões do modelo.

(2) Testamos as relações esperadas entre os construtos do modelo de Tinto via regressão linear para avaliar em que medida as integrações social e acadêmica são mesmo relevantes para a construção das aspirações de futuro dos alunos e em que medida as experiências de integração se relacionam com as motivações de ingresso.

(3) Via análise de correspondência múltipla (GREENACRE, 2007), realizamos uma redução dimensional das variáveis socioeconômicas. Essa redução nos permitiu encontrar as dimensões principais que caracterizam a origem social de cada estudante - bem como visualizar a estrutura das relações entre os estudantes.

(4)Finalmente, testamos a dependência estatística das dimen sões socioeconômicas com as escalas do modelo de Tinto para avaliar em que medida as Motivações, Integrações e Aspirações dos alunos são marcadas por suas origens sociais.

\section{Análise}

\section{Validação do instrumento e construção dos fatores}

Os dados obtidos da aplicação foram testados via Análise Fatorial e de Consistência Interna. Para cada construto do instrumento, foi calculado o alfa de Cronbach. Porém, devido a suspeitas de multidimensionalidade do construto de Motivações, lançamos mão da análise fatorial. A composição dos fatores, sua fidedignidade e as cargas fatoriais podem ser vistas no Apêndice deste artigo.

Por meio da análise fatorial, observamos que o construto de Motivações pode ser mais bem compreendido se for dividido em três fatores ortogonais:

1. As motivações para a licenciatura (ou para o ensino) são mais expressivas entre os estudantes que entraram na Física tendo a docência como objetivo pessoal ("Ingressei no curso de Física acreditando que a carreira de professor me traria satisfação profissional");

2. As motivações para o bacharelado são mais pronunciadas entre aqueles que tinham a pesquisa em seu horizonte quando do ingresso no curso ("Ingressei no curso de Física para me tornar um pesquisador prestigiado"); 
3. As motivações dissonantes, por outro lado, podem estar em desacordo com aquilo que o curso objetivamente é capaz de oferecer. Elas foram inseridas no instrumento com o propósito de buscar os estudantes que ingressam no curso sem nenhum tipo de identificação com ele ou mesmo visando abandoná-lo. Esses casos de evasão não poderiam ser imputados à instituição ("Quando eu entrei na Física, eu já estava interessado em mudar de curso").

A ortogonalidade desses três fatores demonstra que as razões para ingressar no curso de Física podem ser tão diversificadas que fica difícil tomar uma motivação como preditora da outra. Por exemplo, é possível ter motivações alinhadas à pesquisa sem ter motivações voltadas à docência. É igualmente possível estar motivado a ser professor ou pesquisador sem estar suficientemente motivado a concluir o curso.

Os demais três construtos do modelo apresentaram comportamento unidimensional. Como é possível perceber no Apêndice, os itens de integração acadêmica distinguem os estudantes mais confiantes e satisfeitos com seu desempenho acadêmico ("Meu desempenho no curso me estimula a seguir em frente"). A integração social sintetiza as relações de convivência e amizade com os colegas ("Gosto do tempo que passo junto com meus colegas de curso"). Finalmente, as aspirações futuras dizem respeito ao quanto os estudantes têm, atualmente, vontade de concluir o curso. Os itens de aspirações futuras são altamente correlacionados e podem ser interpretados como um medidor sensível da tendência individual à evasão.

\section{Testando o modelo de Tinto}

Baseando-nos no modelo de Tinto (1994), esperamos que os estudantes entrem no curso de graduação com um conjunto de motivações que, atualizadas pelas experiências de integração social e acadêmica, produziria aspirações relacionadas ao abandono do curso ou à permanência nele. Portanto, é esperado que os construtos obtidos na análise fatorial tenham relação de determinação entre si. Ou seja, que as motivações de ingresso no curso influenciem as experiências de integração (social e acadêmica) durante o curso. É esperado que os estudantes previamente motivados a abandonar o curso tenham experiências de integração menos eficientes. Como nosso modelo distingue motivações para a docência e para a pesquisa, é possível avaliarmos se o Instituto de Física discrimina os estudantes segundo suas motivações. Além disso, espera-se que haja uma relação das experiências de integração com as Aspirações de futuro. Ou seja, é esperado que as experiências no curso atualizem as motivações dos estudantes de maneira que os mais integrados (social e academicamente) estejam menos dispostos a evadir.

Para testar as relações do modelo, foram realizadas diversas regressões. Primeiramente, testamos a relação de determinação de cada uma das Integrações (Social e Acadêmica) sobre as Aspirações Futuras (relações à direita na Figura 1). O resultado foi estatisticamente significativo (com $\mathrm{p}<, 05$ ). Os coeficientes de regressão obtidos foram, respectivamente, $\mathbf{0 , 3 3 7}$ e 0,242 para as integrações Acadêmica e Social. Quando inseridas juntas, em um modelo de duas variáveis, a Integração Acadêmica absorve o poder preditivo da Integração Social sobre as Aspirações. Isso pode ser compreendido se observarmos que as duas integrações estão correlacionadas (com coeficiente de correlação igual a 0,300 e $p<0,05$ ). Juntas, essas informações nos levam a conjecturar que a integração acadêmica é mais decisiva que a integração social na construção do desejo de abandonar o curso de Física ou permanecer nele. 
Ao mesmo tempo, precisamos reconhecer que as experiências de integração social e acadêmica costumam estar relacionadas entre si (os estudantes que tiveram suas competências intelectuais reconhecidas pela instituição são geralmente mais inclinados a reportar um convívio regular e agradável com colegas de curso). A relação entre a qualidade do convívio social e o reconhecimento acadêmico dos estudantes não deve ser tomada como evidente, mas precisa ser mais bem compreendida.

Após essa primeira análise, testamos os construtos de Motivação (para a Pesquisa, para a Docência, e Dissonantes) contra os construtos de Integração (Acadêmica e Social). Apenas as Motivações Dissonantes apresentaram poder preditivo sobre as experiências de Integração Acadêmica (com coeficiente de regressão -0,346 e p<0,05). Pessoas que ingressaram no curso com o propósito de abandoná-lo são geralmente menos inclinadas a se tornar estudantes seguros das suas competências acadêmicas. Nenhuma das motivações apresentou poder preditivo sobre a Integração Social.

\section{Variáveis socioeconômicas}

A versão empregada do questionário socioeconômico apresentava diversas informações sobre a residência do estudante, escolaridade, ocupação e renda dos pais. Sobre o local da residência, foram delimitadas quatro zonas segundo estatísticas de violência urbana. As regiões foram enumeradas de Zona 1 a Zona 4 de maneira que, quanto maior o número da zona, maior é a distância até a universidade e mais recorrentes são os casos de violência urbana. Os estudantes do curso de Física que participaram da pesquisa encontramse majoritariamente nas Zonas 1 (31,01\%) e 4 (32,27\%), reforçando a ideia de que estamos diante de uma população muito diversificada do ponto de vista da vulnerabilidade social. Vimos também que, no que tange à mobilidade urbana, muitos estudantes demoram mais de uma hora para chegar à universidade (cerca de 39,24\%), o que possui estreita relação com a localidade da residência. Também observamos que aproximadamente 6 em cada 10 alunos utilizam o transporte público para ir à universidade.

Observamos que a maioria dos alunos não trabalha (112 contra 46). Porém, muitos estão à procura de emprego (44,65\% dentre os que não trabalham). Em consonância com esses dados, aproximadamente 5 em cada 10 alunos da Física não possuem renda própria. Com relação às ocupações dos pais, agrupamos manualmente as respostas seguindo o critério de nível de escolaridade requerido para a profissão. Portanto, codificamos os dados nas seguintes categorias: Fund (ocupações que requerem nível Fundamental), Med/Tec (ocupações de nível Médio ou Técnico), Sup- (ocupações graduadas menos prestigiadas), Sup+ (ocupações graduadas mais prestigiadas) e Dsmpr (Desempregado). Observamos que famílias com ocupações de nível Médio/Técnico são recorrentes entre os estudantes da Física (48,10\% entre os pais e $36,07 \%$ entre as mães). Quanto à escolaridade, uma grande parte das famílias dos respondentes não foram além da educação básica. Por fim, no que diz respeito à escolaridade dos próprios estudantes, a maioria estudou em escolas privadas ou federais: $58,86 \%$ no ensino fundamental e $62,65 \%$ no ensino médio.

Além de perguntas estritamente socioeconômicas (relacionadas ao capital econômico e cultural acumulado pelas famílias), também foram feitas algumas perguntas referentes às práticas dos indivíduos - tais como a quantidade de livros que leem, sua frequência a museus e a quantidade de irmãos. Enfim, para representar a estrutura de relações subjacente a esses 
dados - no sentido empregado por Bourdieu (2007) - recorremos à análise de correspondência múltipla ajustada (GREENACRE, 2007). A Figura 2 apresenta a imagem do mapa gerado a partir da análise desses dados.

No mapa da Figura 2, a dimensão horizontal permite distinguir os alunos em função da sua classe social: à esquerda temos os alunos de classe popular e, à direita, os alunos de classe privilegiada (seja classe média-alta ou elite). Para chegar a essa conclusão analisamos as variáveis presentes nos dois lados do gráfico.

Figura 2 - Mapa simétrico resultante da análise de correspondência múltipla ajustada dos dados socioeconômicos

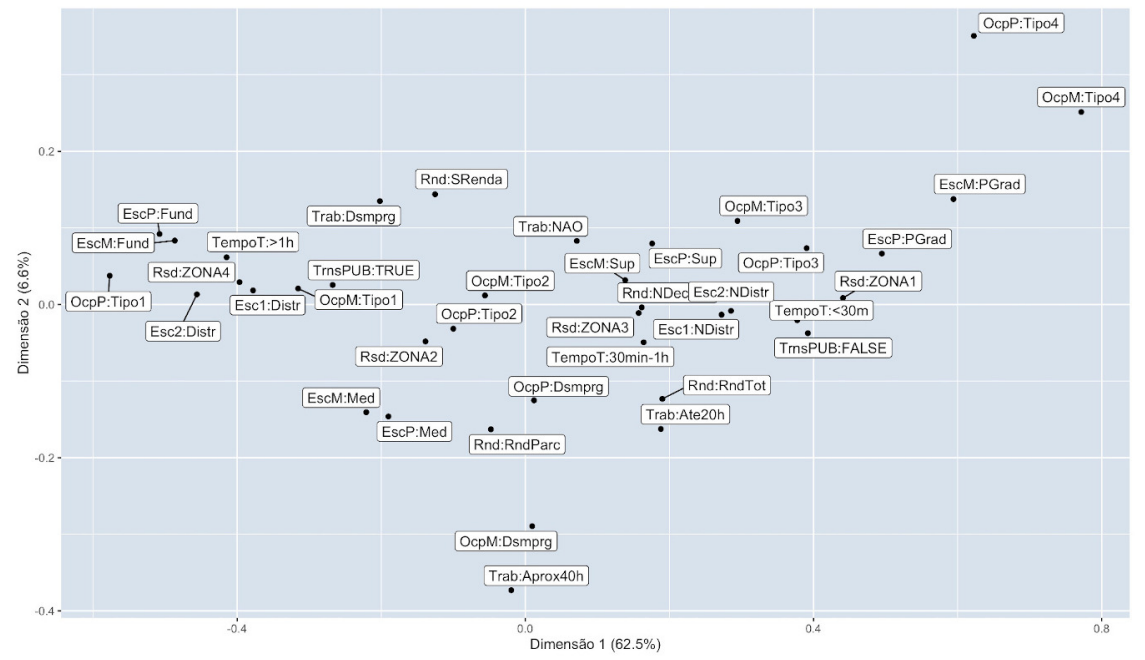

Fonte: elaborada pelos autores.

No que diz respeito à escolaridade e ocupação dos pais vemos que o lado esquerdo reúne as famílias com ocupações populares (OcpP:Tipo1 e OcpM:Tipo1) e escolaridade fundamental (EscP:Fund e EscM:Fund). Ao lado direito acumulam-se as famílias ocupação prestigiada (OcpP:Tipo4 e OcpM:Tipo4) e pós-graduação (EscP:PGrad e EscM:PGrad). Com relação à localidade da moradia dos respondentes, vemos que, ao lado esquerdo, acumulamse os residentes da periferia da cidade (Rsd:ZONA4) - regiões mais violentas e afastadas do campus e do centro da cidade. Em contraste, à direita do mapa, encontram-se os estudantes que residem na região central (Rsd:ZONA1), onde a segurança é maior e o deslocamento ao campus é menor. Em consonância com esses dados observamos que os alunos situados à esquerda demoram mais de uma hora para chegar à universidade (TempoT:>1h), enquanto os alunos situados à direita demoram menos de trinta minutos (TempoT:<30m). Cabe sublinhar que estamos diante de uma cidade incomum, onde o processo de urbanização produziu um centro urbano rico e ordenado, deixando os mais pobres muito afastados da região central. É só por essa razão que as noções geográfica e social de periferia costumam coincidir por aqui.

Outras variáveis que marcam bem a diferença de classe no mapa da Figura 2 são as variáveis de uso do transporte público e o tipo de escolaridade dos respondentes. À esquerda estão os estudantes que usam transporte público para ir à universidade (TrnsPUB:TRUE), enquanto, à direita, não há utilização desse tipo de transporte (TrnsPUB:FALSE). Em relação à escolaridade dos alunos, os respondentes situados à esquerda frequentaram escolas públicas distritais (Esc1:Distr, Esc2:Distr), enquanto que, ao lado direito, os respondentes frequentaram escolas privadas ou federais (Esc1:NDistr, Esc2:NDistr). 


\section{Origem Social e Experiência no Curso}

Finalmente, como parte da análise de correspondência realizada na seção anterior, testamos a correlação entre as variáveis do modelo de Tinto e as dimensões de origem social que emergiram no mapa da Figura 2. Esses testes foram realizados com o propósito de identificar o papel das diferenças sociais na produção da evasão do curso de Física. Cabe lembrar que as taxas de evasão do ensino superior, ao contrário do que ocorre na educação básica, podem ser consideradas pouco sensíveis às desigualdades sociais. Afinal, entre os estudantes que abandonam os cursos de graduação, encontram-se também alguns privilegiados que buscam cursos mais prestigiados ou que não precisam da universidade para garantir sua posição.

Os testes indicam (com $\mathrm{p}<0,05$ ) que a Integração social e acadêmica, além de correlacionadas entre si e com as Aspirações de futuro, estão relacionadas à origem social. A dimensão 1 do mapa da Figura 2, que distingue classe popular e dominante, tem correlação igual a 0,254 com a integração social e 0,208 com a integração acadêmica. Todos os demais testes resultaram não significativos. Disso resulta que os estudantes de periferia tendem a se sentir menos integrados social e academicamente ainda que não haja diferenças motivacionais expressivas entre eles e os estudantes mais privilegiados.

\section{Considerações Finais}

Uma característica simples, mas importante, que marca o perfil dos estudantes de graduação no Brasil é que os filhos da classe popular vêm geralmente da escola pública estadual enquanto as famílias mais privilegiadas colocam seus filhos na rede privada. Esse padrão é particularmente relevante para entendermos como a precarização das redes estaduais integra a experiência dos estudantes de ciências na educação superior. É verdade que, quanto mais uniformes forem os métodos de ensino e avaliação, mais o sistema educacional contribuirá para traduzir diferenças sociais em diferenças escolares (LIMA JUNIOR; OSTERMANN; REZENDE, 2018). Porém, é inegável que o sistema educacional brasileiro não é uniforme, mas altamente diferenciado, e que, por sua própria construção desigual, dá mais oportunidades aos mais privilegiados.

Baseado no modelo de Tinto (1994), este artigo investigou as relações entre a integração dos estudantes do Instituto de Física da UnB e sua origem social. Além de decidir pela aplicabilidade do modelo de Tinto (confirmando que as experiências de integração acadêmica e social são importantes para construir as aspirações de permanência no curso), a análise permitiu concluir que:

(1) Entre os ingressantes, a ocorrência de motivação para a docência é independente da motivação para pesquisa, pois os fatores de motivação não são correlacionados entre si;

(2) Estudantes mais seguros das suas competências intelectuais são também os que reportam um convívio mais regular e agradável com os colegas, pois as integrações acadêmica e social são positivamente correlacionadas entre si;

(3) Os estudantes de periferia tendem a ser menos integrados social e academicamente, ainda que não haja diferenças motivacionais significativas entre eles e os estudantes mais privilegiados ao ingressar no curso. 
Como primeiro resultado, observamos que os estudantes entram no curso de Física com motivações diferentes e pouco correlacionadas entre si (ortogonais). Ser motivado para lecionar Física na educação básica não elimina nem amplifica a motivação para ser pesquisador. A probabilidade de estar interessado em desempenhar as duas funções, uma das duas ou nenhuma foi aproximadamente igual na nossa amostra. Apesar da separação, no imaginário comum e na organização institucional, entre os que fazem pesquisa e os que ensinam, ao ingressar no curso, essas motivações aparecem igualmente misturadas.

Sobre a correlação observada entre integração acadêmica e social, percebemos que a imagem do estudante bon vivant - integrado à vida social, mas desintegrado da vida acadêmica - não foi retratada pelos dados. A correlação entre integração social e acadêmica indica que os alunos mais bem relacionados são também os mais seguros de sua competência acadêmica, e que o reconhecimento acadêmico dos estudantes (aprovação e reprovação nas avaliações, por exemplo) cumpre um papel muito importante na forma como eles se relacionam uns com os outros. Em outras palavras, a correlação entre integração acadêmica e social quer dizer que os estudantes mais seguros das suas competências e mais reconhecidos intelectualmente são também os que reportam um convívio mais agradável com os colegas. Tudo indica que os efeitos de uma educação básica mais precária - típica da classe popular - reflete substancialmente nas possibilidades de estabelecer conexões afetivas e se sentir parte integral da comunidade do Instituto de Física.

Há, é claro, alguns obstáculos bastante práticos para os estudantes de classe popular. Além de serem mais propensos à reprovação, é usual que eles tenham emprego durante o dia e que estudem à noite - seja pela necessidade real de se manter, seja pela falta do rigorismo ascético que caracteriza os investimentos escolares da classe média. Assim, ocupados durante boa parte do dia, restam-Ihes menos oportunidades de participar da vida social e acadêmica da instituição. Por outro lado, para os que não estão empregados em jornadas de 40 horas semanais, os cursos noturnos representam uma oportunidade importante de integração social. Afinal, estudantes com o dia livre poderão atuar de forma intensiva em projetos de pesquisa e extensão. De fato, a diversificação dos currículos, por meio de ações de pesquisa e extensão com oferta de bolsa pode ter um papel crucial na fixação dos estudantes nos cursos de graduação em ciências (MASSI; VILLANI, 2015). O oferecimento de bolsas pode ser decisivo no sentido de chamar a atenção de alunos desfavorecidos, fazendo com que haja a possibilidade de conseguir se manter na IES mesmo sem trabalhar. No que diz respeito a possível defasagem em conteúdo que alunos do Ensino Médio podem trazer, o Instituto de Física possui uma matéria optativa que procura ajudar esses alunos com um nível introdutório de cálculo aplicado à Física. O retorno costuma ser satisfatório e ajuda alunos a tirarem parte do medo que possam ter de matérias do nível superior, mas as taxas de evasão continuam elevadas.

Enfim, retornando à questão de pesquisa (em que medida a integração acadêmica $e$ social dos estudantes do Instituto de Física da Universidade de Brasília varia segundo a origem social desses estudantes?), percebemos que as integrações acadêmica e social representam uma questão de classe. Estudantes de diferentes origens sociais entram igualmente motivados para o curso de Física, mas os menos favorecidos (cultural ou economicamente) tendem a ser menos integrados à vida social e acadêmica da instituição. Portanto, ainda que os índices de evasão não costumem ser muito sensíveis à origem social dos estudantes, os filhos da periferia da cidade são mais propensos a abandonar o curso por razões propriamente institucionais. 


\section{Agradecimentos}

Os autores agradecem o apoio do Conselho Nacional de Pesquisa, CNPq (processo 436910/2018-7); Fundação de Apoio à Pesquisa do Distrito Federal, FAPDF (processo 00193.00002099/2018-65) e Decanato de Pesquisa e Graduação da Universidade de Brasília (processo 23106.108908/2017-34).

\section{Referências}

BOURDIEU, P. A distinção: crítica social do julgamento. São Paulo: EDUSP, 2007.

BOURDIEU, P.; PASSERON, J.-C. A reprodução. 3. ed. Rio de Janeiro: Francisco Alves, 1992.

BRAXTON, J. M.; HIRSCHY, A. S.; MCCLENDON, S. A. Understanding and reducing college student departure. ASHE Higher Education Report, Hoboken, v. 30, n. 3, p. 1-105, 2004. Disponível em: https:// onlinelibrary.wiley.com/toc/15360709/30/3. Acesso em: 14 jun. 2020.

CEREZO, L. El ingreso a la universidad de jóvenes en situación de vulnerabilidad social: razones y factores que los motivan. Revista Iberoamericana de Educación Superior, Mexico, v. 9, n. 25, p. 62-84. 2018. Disponível em: https://tinyurl.com/y86fnt4b. Acesso em: 30 jun. 2020.

GREENACRE, M. Correspondence analysis in practice. New York: Chapman \& Hall, 2007.

KLEINKE, M. U. Influência do status socioeconômico no desempenho dos estudantes nos itens de física do ENEM 2012. Revista Brasileira de Ensino de Física, São Paulo, v. 39, n. 2, 2017. DOI: http://doi. org/d2bz.

KUSSUDA, S. K. Um estudo sobre a evasão em um curso de licenciatura em física: discursos de ex-alunos e professores. 2017. Tese (Doutorado em Educação para a Ciência) - Faculdade de Ciências, Universidade Estadual Paulista, Bauru, 2017. Disponível em: https://repositorio.unesp.br/ handle/11449/152951. Acesso em: 30 jun. 2020.

LEMOS, I. B. Narrativas de cotistas raciais sobre suas experiências na universidade. Revista Brasileira de Educação, Rio de Janeiro, v. 22, n. 71, e227161, 2017. DOI: http://doi.org/d253

LIMA JUNIOR, P. Crítica sociológica do Exame Nacional do Ensino médio: uma análise bourdiana. In: ENCONTRO DE PESQUISA EM ENSINO DE FÍSICA, 10., 2015, Águas de Lindóia. Atas [...]. São Paulo: SBF, 2015. Disponível em: https://tinyurl.com/ybd5ugrq. Acesso em: 30 jun. 2020.

LIMA JUNIOR, P.; OSTERMANN, F.; REZENDE, F. Razões para desistir: análise sociológica da evasão do curso de física. Curitiba: Appris, 2018.

MASSI, L.; VILLANI, A. Um caso de contratendência: baixa evasão na licenciatura em química explicada pelas disposições e integrações. Educação e Pesquisa, São Paulo, v. 41, n. 4, p. 975-992, 2015. DOI: http://doi.org/cj7g.

MENDES JUNIOR, A. A. F. Uma análise da progressão dos alunos cotistas sob a primeira ação afirmativa brasileira no ensino superior: o caso da Universidade do Estado do Rio de Janeiro. Ensaio, Belo Horizonte, v. 22, n. 82, p. 31-56, 2014. DOI: http://doi.org/d254.

MONT'ALVÃO, A. Estratificação educacional no Brasil do século XXI. Dados, Rio de Janeiro, v. 54, n. 2, p. 389-430, 2011. DOI: http://doi.org/d2bw. 
OECD. PISA 2015 results: volume a: excellence and equity in education. Paris: OECD Publishing, 2016. DOI: http://doi.org/bv9k.

PASCARELLA, E.T.; TERENZINI, P.T. How college affects students: findings and insights from twenty years of research. Hoboken: Jossey-Bass, 1991.

PEIXOTO, A. L. A.; RIBEIRO, E. M. B. A.; BASTOS, A. V. B.; RAMALHO, M. C. K. Cotas e desempenho acadêmico na UFBA: um estudo a partir dos coeficientes de rendimento. Avaliação, Campinas, v. 21, n. 2, p. 569-592, 2016. DOI: http://doi.org/d2b2.

RIBEIRO, E. Evasão e permanência num curso de licenciatura em física: o ponto de vista dos licenciandos. 2015. Dissertação (Mestrado em Educação) - Universidade Federal do Paraná, Curitiba, 2015. Disponível em: https://acervodigital.ufpr.br/handle/1884/41185. Acesso em: 30 jun. 2020.

RISTOFF, D. Evasão: exclusão ou mobilidade. Florianópolis: UFSC, 1995.

RISTOFF, D. Vinte e um anos de educação superior: expansão e democratização. Cadernos do GEA, Rio de Janeiro, n. 3, p. 3-50. 2013. Disponível em: https://tinyurl.com/y9swd6nh. Acesso em: 30 jun. 2020.

SILVA FILHO, R. L. L.; MOTEJUNAS, P. R.; HIPOLITO, O.; LOBO, M. B. C. M. A evasão no ensino superior brasileiro. Cadernos de Pesquisa, São Paulo, v. 37, n. 132, p. 641-659. 2007. DOI: http://doi.org/ cw436v.

TINTO, V. Leaving college: rethinking the causes and cures of students attrition. 2nd. ed. Chicago: Chicago University Press, 1994.

WAINER, J.; MELGUIZO, T. Políticas de inclusão no ensino superior: avaliação do desempenho dos alunos baseado no Enade de 2012 a 2014. Educação e Pesquisa, v. 44, e162807, 2018. DOI: http://doi. org/d2b3.

Apêndice A - composição dos fatores, sua fidedignidade e cargas fatoriais

Ao lado de cada fator, encontra-se seu alfa de Cronbach. Ao lado de cada item foi publicada a carga desse item no referido fator (as cargas indicam o quanto o item é relevante para o referido fator).

\section{Motivação para o bacharelado (alfa $=0,8)$}

Ao ingressar no curso de Física, eu já desejava trabalhar na área $(\mathbf{0}, 56)$

Quando eu ingressei na Física, eu queria ser pesquisador $(\mathbf{0}, \mathbf{8 0})$

Quando eu ingressei na graduação em Física, eu já planejava fazer pós-graduação na área do curso $(\mathbf{0 , 6 1 )}$

Eu não ingressei no curso de Física para ser cientista $(-0,74)$

Ao ingressar no curso, eu pretendia contribuir para o desenvolvimento científico e tecnológico do país $(\mathbf{0}, \mathbf{5 3})$

Ingressei no curso de Física para me tornar um pesquisador prestigiado $(\mathbf{0 , 8 3})$

Desde o ingresso no curso, eu tinha interesse em investigar alguns temas atuais da Física $(\mathbf{0 , 6 1 )}$ 


\section{Motivação para a licenciatura (alfa $=0,80)$}

Ingressei no curso de Física acreditando que a carreira de professor me traria satisfação profissional $(0,92)$

Quando eu ingressei na Física, eu tinha interesse em ser professor de Física $(\mathbf{0 , 9 1 )}$

Na época em que entrei no curso de Física, eu não tinha interesse em ministrar aulas da educação básica $(-0,56)$

Ingressei no curso de Física esperando salário e empregabilidade $(\mathbf{0}, 49)$

$$
\text { Motivações dissonantes (alfa }=0,83 \text { ) }
$$

A baixa concorrência foi um elemento importante na minha escolha pelo curso de Física $(\mathbf{0 , 6 7})$ Quando eu entrei na Física, eu já estava interessado em mudar de curso $(\mathbf{0 , 6 4 )}$ Ingressei no curso de Física apenas para ter um diploma de ensino superior, independente do curso $(0,51)$

Minha escolha pela Física levou em consideração a nota de corte para ingresso no curso $(\mathbf{0 , 7 5 )}$ Ao ingressar na Física eu não fazia questão de trabalhar na área do curso $(0,57)$ Tenho interesse apenas no conteúdo deste curso, mas não necessariamente em seguir carreira na Física $(0,47)$

$$
\text { Integração social (alfa }=0,76)
$$

Não tenho tempo de lazer com meus colegas de curso $(-0,43)$

Desenvolvi amizades no curso de Física $(\mathbf{0 , 7 6})$

Não sinto pertencimento com relação aos meus colegas de curso $(-\mathbf{0 , 6 3 )}$

Gosto do tempo que passo junto com meus colegas de curso $(\mathbf{0 , 8 1})$

O curso de Física me ajudou a me relacionar com outras pessoas $(0,54)$

Eu me sinto discriminado ou sofro algum tipo de preconceito $(-0,31)$

Acho desgastante o convívio com alguns colegas de curso $(-0,19)$

$$
\text { Integração acadêmica }(\text { alfa }=0,85)
$$

Eu me sinto desmoralizado pela dificuldade do curso $(0,69)$

Estou satisfeito com meu desempenho no curso $(-\mathbf{0 , 6 0 )}$

Tenho sensação de não pertencimento à comunidade do IF $(\mathbf{0}, \mathbf{4 6})$

Meu desempenho no curso me estimula a seguir em frente $(-0,72)$

Tenho me sentido incapaz de prosseguir com o curso de Física $(\mathbf{0}, \mathbf{7 5})$

Eu me sinto pouco inteligente diante da comunidade do IF $(\mathbf{0 , 7 2})$

Apesar dos meus esforços, não consigo melhorar meu rendimento acadêmico $(0,73)$

\section{Aspirações futuras (alfa $=0,88$ )}

Estou considerando a possibilidade de trancar temporariamente o curso de Física $(\mathbf{0 , 5 6 )}$

Pretendo concluir o curso de Física apesar de quaisquer dificuldades $(-0,83)$

Estou considerando a possibilidade de abandonar o curso de Física $(\mathbf{0 , 8 7})$

Desejo mudar da Física para outro curso de graduação $(\mathbf{0 , 8 0})$

Desejo trabalhar na área do curso de Física assim que concluir minha formação $(-0,54)$

Não tenho expectativas reais de concluir o curso de Física $(0,77)$

Pretendo cursar mestrado na área de Física ou Ensino de Física $(-0,59)$ 